\title{
Investigation of the Geochemical Preservation of ca. 3.0 Ga Permineralized and Encapsulated Microfossils by Nanoscale Secondary Ion Mass Spectrometry
}

\author{
Frédéric Delarue, ${ }^{1}$ François Robert, ${ }^{1}$ Kenichiro Sugitani, \\ Romain Tartèse, ${ }^{1}$ Rémi Duhamel, ${ }^{1}$ and Sylvie Derenne ${ }^{3}$
}

\begin{abstract}
Observations of Archean organic-walled microfossils suggest that their fossilization took place through both encapsulation and permineralization. In this study, we investigated microfossils from the $\mathrm{ca}$. 3.0 Ga Farrel Quartzite (Pilbara, Western Australia) using transmitted light microscopy, scanning electron microscopy, Raman microspectrometry, and nanoscale secondary ion mass spectrometry (NanoSIMS) ion microprobe analyses. In contrast to previous studies, we demonstrated that permineralized microfossils were not characterized by the micrometric spatial relationships between Si and C-N as observed in thin sections. Permineralized microfossils are composed of carbonaceous globules that did not survive the acid treatment, whereas encapsulated microfossils were characterized due to their resistance to the acid maceration procedure. We also investigated the microscale relationship between the ${ }^{12} \mathrm{C}^{14} \mathrm{~N}^{-}$and ${ }^{12} \mathrm{C}_{2}{ }^{-}$ion emission as a proxy of the N/C atomic ratio in both permineralized and encapsulated microfossils. After considering any potential matrix and microtopography effects, we demonstrate that the encapsulated microfossils exhibit the highest level of geochemical preservation. This finding shows that the chemical heterogeneity of the microfossils, observed at a spatial resolution of a few hundreds of micrometers, can be related to fossilization processes. Key Words: Carbonaceous matter-Farrel Quartzite-Fossilization-NanoSIMS—Nitrogen-Permineralization. Astrobiology 17, 1192-1202.
\end{abstract}

\section{Introduction}

M ICROFOSSIL-LIKE STRUCTURES have been reported in numerous Archean rocks (e.g., Walsh, 1992; Schopf, 1993; Javaux et al., 2010; Sugitani et al., 2010). As a result of thermal alteration, however, their morphological features and their geochemical composition had often been severely modified, making the univocal identification of microorganisms and associated metabolism difficult. Microorganisms are generally thought to be fossilized through permineralization resulting from the "early infiltration and permeation of tissues by mineral-charged water" (Schopf, 1975). Consequently, the organic remnants are progressively replaced by silica or carbonates during mineralization. However, the presence of organic-walled microfossils in some Archean rocks (Grey and Sugitani, 2009; Javaux et al. 2010; Sugitani et al., 2015) points to the existence of other mechanisms of fossilization, such as encapsulation of microorganisms through, for example, nucleation of adjacent mineral crystals (Rainey and Jones, 2010). Through investigation of mineralization of microbial mats from Icelandic hot springs, Konhauser and Ferris (1996) proposed that encapsulation favors morphological and geochemical preservation of microorganisms. This is supported by experimental silicification of modern microorganisms, which shows that the negative effect on geochemical preservation caused by thermal alteration can be counterbalanced by encapsulation (Picard et al., 2015). However, encapsulation has not yet been directly documented in Archean rocks despite its great potential for preservation of microorganisms.

Bulk N/C atomic ratio has been classically used as a proxy to characterize the preservation status of organic matter (Watanabe et al., 1997; Beaumont and Robert, 1999). However, this bulk geochemical approach neglects potential

\footnotetext{
${ }^{1}$ IMPMC Sorbonne Universités-MNHN, UPMC Univ Paris 06, UMR CNRS 7590, IRD UMR 206, Paris, France.

${ }^{2}$ Department of Environmental Engineering and Architecture, Graduate School of Environmental Studies, Nagoya University, Nagoya, Japan.

${ }^{3}$ Sorbonne Universités, UPMC Univ Paris 06, CNRS, UMR 7619 METIS, Paris, France.

(C) Frédéric Delarue et al., 2017; Published by Mary Ann Liebert, Inc. This Open Access article is distributed under the terms of the Creative Commons License (http://creativecommons.org/licenses/by/4.0), which permits unrestricted use, distribution, and reproduction in any medium, provided the original work is properly credited.
} 
heterogeneities in preservation among different organic remnants. Recent technological developments, notably in the field of secondary ion mass spectrometry, have allowed in situ elemental and isotopic investigations of putative microfossils at the micro- to nanoscale (Oehler et al., 2009; House et al., 2013). Notably, it has been shown that the ${ }^{12} \mathrm{C}^{14} \mathrm{~N}^{-} /{ }^{12} \mathrm{C}_{2}^{-}$molecular ionic ratio is strongly correlated with bulk N/C atomic ratio (Thomen et al., 2014; Alleon et al., 2015), opening up the possibility to evaluate the geochemical preservation of Archean microfossils at the micrometer scale. In pioneering studies, Oehler et al. (2009, 2010) used nanoscale secondary ion mass spectrometry (NanoSIMS) analyses to calculate in situ N/C atomic ratios ranging from $\mathrm{ca}$. 0.0125 to 0.05 for Archean spheroid microfossils from $3.0 \mathrm{Ga}$ cherts. However, the possible effects of microtopography on the ${ }^{12} \mathrm{C}^{14} \mathrm{~N}^{-} /{ }^{12} \mathrm{C}_{2}^{-}$molecular ratios determined for the microfossils studied by Oehler et al. (2009, 2010) have not been thoroughly evaluated, and it is known that microtopography may induce relatively large changes in ${ }^{12} \mathrm{C}^{14} \mathrm{~N}^{-} /{ }^{12} \mathrm{C}_{2}^{-}$ratios even though precise quantifications are still incomplete (e.g., Thomen et al., 2014; Alleon et al., 2015). These potential analytical pitfalls have to be addressed to further evaluate the significance of the relatively high in situ N/C atomic values determined by Oehler et al. $(2009,2010)$ for Archean microfossils. In this respect, a recent study has highlighted that silicification promoted the exceptional geochemical preservation of organic microfossils in the $1.88 \mathrm{Ga}$ Gunflint cherts that have $\mathrm{N} / \mathrm{C}$ atomic ratios up to $c a .0 .25-0.30$ (Alleon et al., 2016), which is commensurable with the $\mathrm{N} / \mathrm{C}$ ratios of modern cyanobacteria and is, by far, higher than the N/C ratios determined by Oehler et al. (2009, 2010).

In this study, our purposes are (i) to provide a procedure to determine the preservation status of organic microfossils by studying the relationship between the emissions of the ${ }^{12} \mathrm{C}_{2}^{-}$and ${ }^{12} \mathrm{C}^{14} \mathrm{~N}^{-}$molecular ions in pure organic standards, kerogens, and microfossils from both thin sections and acid maceration residues and (ii) to discuss the effect of the process of fossilization, that is, permineralization versus encapsulation, on the geochemical preservation of microfossils from the 3.0 Ga Farrel Quartzite.

\section{Material and Methods}

\subsection{Sample locality}

A black chert sample was collected from the $c a .3 .0 \mathrm{Ga}$ Farrel Quartzite at the Mount Grant locality in the Goldsworthy greenstone belt, in the Pilbara Craton in Western Australia. The Farrel Quartzite is composed of a clastic formation up to $80 \mathrm{~m}$ thick containing fine-grained to very coarse-grained sandstone, including quartzite with minor conglomerate, mafic to ultramafic volcanoclastic layers, evaporite beds, and black chert layers (Sugitani et al., 2007). This unit underwent greenschist facies metamorphism and was pervasively silicified. The $c a .30 \mathrm{~cm}$ thick microfossilbearing black chert occurs in the uppermost part of the Farrel Quartzite and is closely associated with evaporite beds.

\subsection{Analyses}

2.2.1. Sample preparations and microscopy. Transmission light microscopy (TLM) observations and NanoSIMS analyses were carried out on both rock thick sections (thickness of $c a .50 \mu \mathrm{m})$ and isolated kerogen, whereas scanning electron microscopy (SEM) observations were only performed on the kerogen. Kerogen isolation was performed on about $200 \mathrm{~g}$ of rock through successive demineralization using $\mathrm{HF}-\mathrm{HCl}$ (Derenne et al., 2008). Then, a few milligrams of kerogen was deposited on a microscope glass slide for TLM, SEM, and NanoSIMS investigations. Carbonaceous microfossils were first observed with TLM in order to define targets of interest. Then glass slides were directly gold coated $(20 \mathrm{~nm}$ thick) for SEM energy dispersive X-ray spectroscopy analysis and imaging using a TESCAN VEGA II at the French National Museum of Natural History (MNHN) with an accelerating voltage of $15 \mathrm{kV}$.

2.2.2. Raman microspectrometry. Raman spectra were obtained with a Renishaw InVIA microspectrometer, equipped with a $532 \mathrm{~nm}$ argon laser. The laser was focused on the sample by using a DMLM Leica microscope with a $50 \times$ objective. The spectrometer was first calibrated with a silicon standard before the analytical session. For each target, we determined the Raman shift intensity in the spectral window from 1000 to $1900 \mathrm{~cm}^{-1}$ including the first-order disorder carbon (D) and graphite $(\mathrm{G})$ bands. A laser power below $1 \mathrm{~mW}$ was used to prevent any thermal alteration during the spectra acquisition. Finally, spectra acquisition was achieved after three successive iterations using a time exposure of $40 \mathrm{~s}$.

2.2.3. Nanoscale secondary ion mass spectrometry. Standards and microfossils were analyzed with the CAMECA NanoSIMS 50 at the MNHN. Before measurements, presputtering is required (i) to avoid surficial contamination and (ii) to achieve the saturation fluence of implemented cesium $\left(\mathrm{Cs}^{+}\right)$in order to obtain constant secondary ion count rates and then a constant ${ }^{12} \mathrm{C}^{14} \mathrm{~N}^{-} /{ }^{12} \mathrm{C}_{2}^{-}$ionic ratio (Fig. 1). Hence, $\mathrm{Cs}^{+}$was implanted by using a $200 \mathrm{pA}$ primary current $(300 \mu \mathrm{m}$ aperture diaphragm $)$ on $50 \times 50$ to $75 \times 75 \mu \mathrm{m}^{2}$ areas, depending of the size of each target. Analyses were then carried out by using a $5 \mathrm{pA}$ primary current $(150 \mu \mathrm{m}$ aperture diaphragm) on smaller areas to avoid presputtering edge artifacts. Secondary molecular ions and species of ${ }^{12} \mathrm{C}_{2}^{-},{ }^{12} \mathrm{C}^{14} \mathrm{~N}^{-}$, and ${ }^{28} \mathrm{Si}^{-}$were collected simultaneously in electron multipliers. NanoSIMS raw data were corrected for a $44 \mathrm{~ns}$ dead time on each electron multiplier and were processed with the Limage software

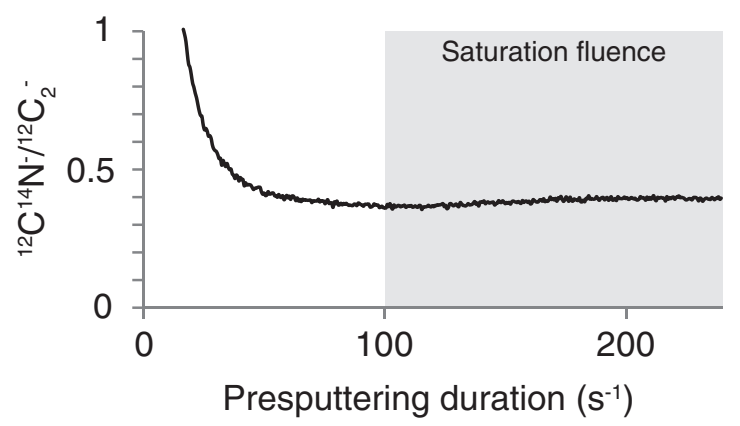

FIG. 1. ${ }^{12} \mathrm{C}^{14} \mathrm{~N}^{-} /{ }^{12} \mathrm{C}_{2}^{-}$ratio recorded as a function of the presputtering duration. The gray area indicates the time window in which the saturation fluence was achieved on the resin standard. Saturation fluence was systematically controlled for each studied microfossil. 
(developed by L. Nittler, Carnegie Institution, Washington, DC, USA). The external reproducibility was determined through multiple measurements of the emissions of the ${ }^{12} \mathrm{C}^{14} \mathrm{~N}^{-}$and ${ }^{12} \mathrm{C}_{2}{ }^{-}$molecules on a coal standard used by Thomen et al. (2014). A second NanoSIMS session was dedicated to the analyses of a blank (polycarbonate filter), pure organic standards (resin and tryptophan), and a type III kerogen (land plant-derived carbonaceous matter). These pure standards and the type III kerogen correspond to the standards previously used in the work of Alleon et al. (2015). Hence, $\mathrm{Cs}^{+}$was implanted by using a $400 \mathrm{pA}$ primary current $(150 \mu \mathrm{m}$ aperture diaphragm $)$ on $45 \times 45 \mu \mathrm{m}^{2}$ areas. Analyses were then carried out by using a $1 \mathrm{pA}$ primary current $(150 \mu \mathrm{m}$ aperture diaphragm) on smaller areas to avoid presputtering edge artifacts.

2.2.4. Statistics and errors. Correlations between the ${ }^{12} \mathrm{C}_{2}{ }^{-}$and ${ }^{12} \mathrm{C}^{14} \mathrm{~N}^{-}$and ${ }^{28} \mathrm{Si}^{-}$ion emissions were tested with Spearman's rank correlation. A $p$ value inferior to 0.05 is indicative of a significant correlation. In the presence of a significant spatial relationship between the emissions of ions, linear regressions were performed to calculate the value of the slope and its associated standard error $\left(1 \sigma_{\text {reg }}\right)$ following

$$
1 \sigma_{\text {reg }}=\sqrt{\sum(\mathrm{yi}-\hat{\mathrm{yi}})^{2} /(n-2)} / \sqrt{\Sigma(\mathrm{xi}-\overline{\mathrm{x}})^{2}}
$$

where yi is the emission of the ${ }^{12} \mathrm{C}^{14} \mathrm{~N}^{-}$ion measured by NanoSIMS, ŷi is the emission of the ${ }^{12} \mathrm{C}^{14} \mathrm{~N}^{-}$ion determined by linear regression, $x i$ is the emission of the ${ }^{12} \mathrm{C}_{2}^{-}$ion measured by NanoSIMS, $\bar{x}$ is the average value of the emissions of the ${ }^{12} \mathrm{C}_{2}^{-}$ion, and where $n$ is the number of regions of interest (ROIs).

The external reproducibility was determined by determining the slope of the regression line between the ${ }^{12} \mathrm{C}_{2}{ }^{-}$and ${ }^{12} \mathrm{C}^{14} \mathrm{~N}^{-}$ion emissions of a coal standard $(n=7)$. Then, the standard error of the mean slope $\alpha\left(1 \sigma_{\text {rep }}\right)$ was calculated.

Finally, the total error $\left(1 \sigma_{\mathrm{tot}}\right)$ was determined as follows:

$$
1 \sigma_{\text {tot }}=\sqrt{1 \sigma_{\text {reg }}^{2}+1 \sigma_{\text {rep }}^{2}}
$$

\section{Results}

\subsection{Carbonaceous microfossils in thin section and kerogen}

A morphological diversity of microfossils was observed in thin section, with assemblages of lenticular (formerly described as spindle-like; ca. 20-40 $\mu \mathrm{m}$; Sugitani et al., 2007, 2009; Grey and Sugitani, 2009), film-like (>100 $\mu \mathrm{m})$, and spheroidal (mainly $<15 \mu \mathrm{m}$ ) microfossils occurring either as isolated specimens or as clusters (Fig. 2). In both spheroids and lenticular structures analyzed in thin sections, the ${ }^{12} \mathrm{C}_{2}-$ and ${ }^{12} \mathrm{C}^{14} \mathrm{~N}^{-}$ion emissions (Fig. 2a, 2b) are found within the siliceous matrix. In the film-like microstructure (Fig. 2c), the ${ }^{12} \mathrm{C}_{2}^{-}$and ${ }^{12} \mathrm{C}^{14} \mathrm{~N}^{-}$are emitted with almost no emission of ${ }^{28} \mathrm{Si}^{-}$. This observation illustrates the fact that this microstructure was encapsulated by the siliceous matrix.

Characterizing microfossils from thin sections with NanoSIMS implies that the analyzed targets occur at the very surface of the sample because the intensity of the

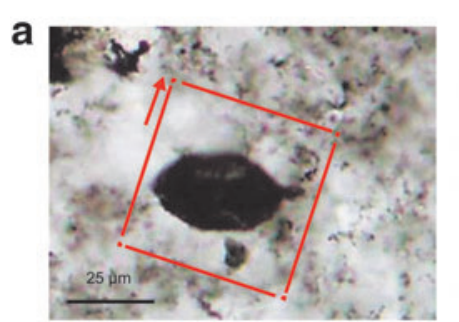

b

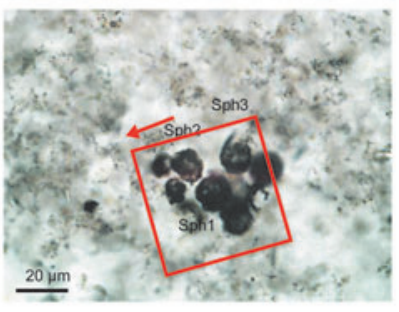

C

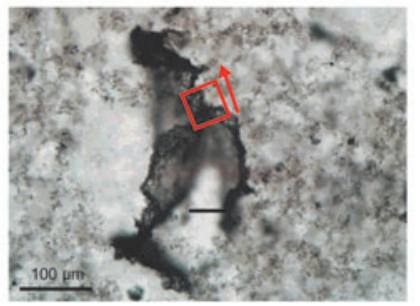

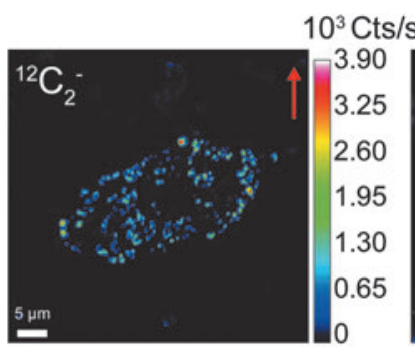
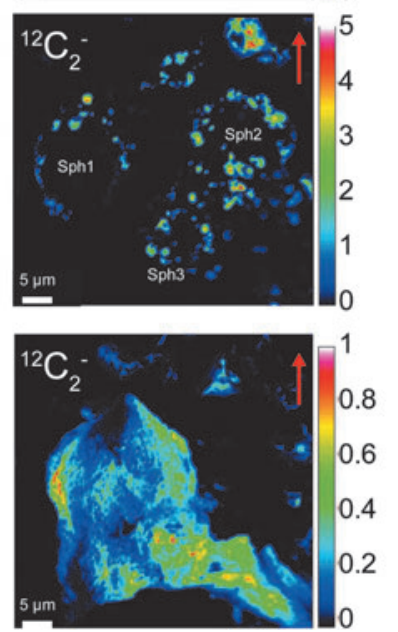

$10^{3} \mathrm{Cts} / \mathrm{s}$
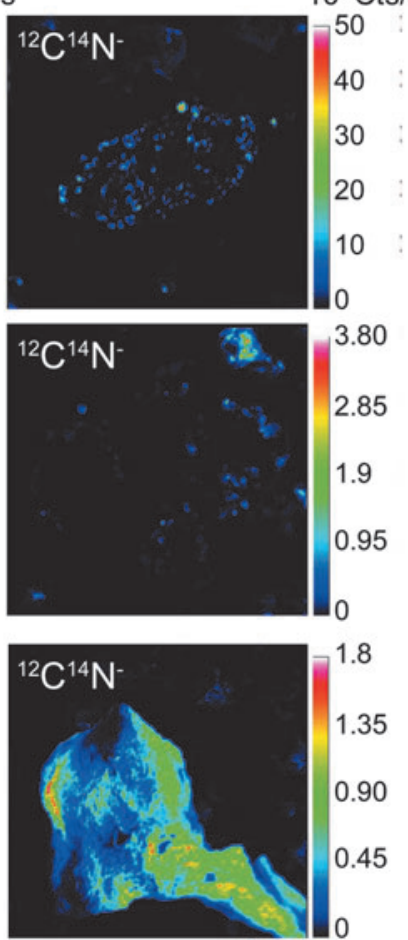
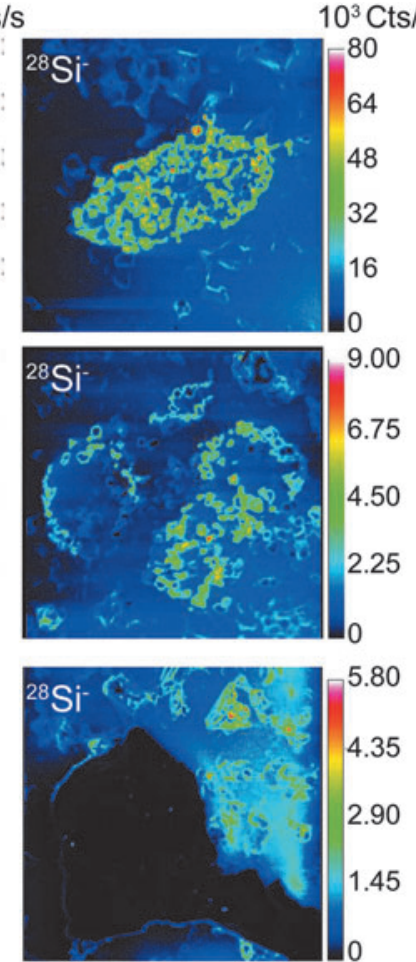

FIG. 2. Transmitted light photomicrographs and NanoSIMS ion images $\left({ }^{12} \mathrm{C}_{2}-{ }^{12} \mathrm{C}^{14} \mathrm{~N}^{-}\right.$, and $\left.{ }^{28} \mathrm{Si}^{-}\right)$of $(\mathbf{a})$ a lenticular-like microfossil, (b) a spheroid cluster, and (c) a film-like microfossil. The microfossils were all observed on thin section. On each photomicrograph, the red dashed square outline indicates the area investigated by NanoSIMS. 
primary beam cannot sputter more than a few atomic layers in depth. Therefore, the amount of microfossil targets in thin sections is limited. On the contrary, the kerogen fraction obtained by $\mathrm{HF}-\mathrm{HCl}$ maceration of the fossil-bearing black cherts contains some microfossils morphologically equivalent to those in thin section (Grey and Sugitani, 2009). Although spheroids identified in the thin section were not found in the kerogen residue, lenticular and film-like microfossils were also observed in the kerogen fraction (Fig. 3). These lenticular and film-like microfossils are characterized by Raman line shape (Fig. 4), which is consistent with previous Raman spectra determined on microfossils from thin section (Sugitani et al., 2007).

\subsection{NanoSIMS quantitative investigation}

The N/C atomic ratio has been classically used to assess the preservation status of ancient organic matter (Watanabe et al., 1997; Beaumont and Robert, 1999). For NanoSIMS analysis, the ${ }^{12} \mathrm{C}^{14} \mathrm{~N}^{-} /{ }^{12} \mathrm{C}_{2}^{-}$ionic ratio has been regarded as a

a
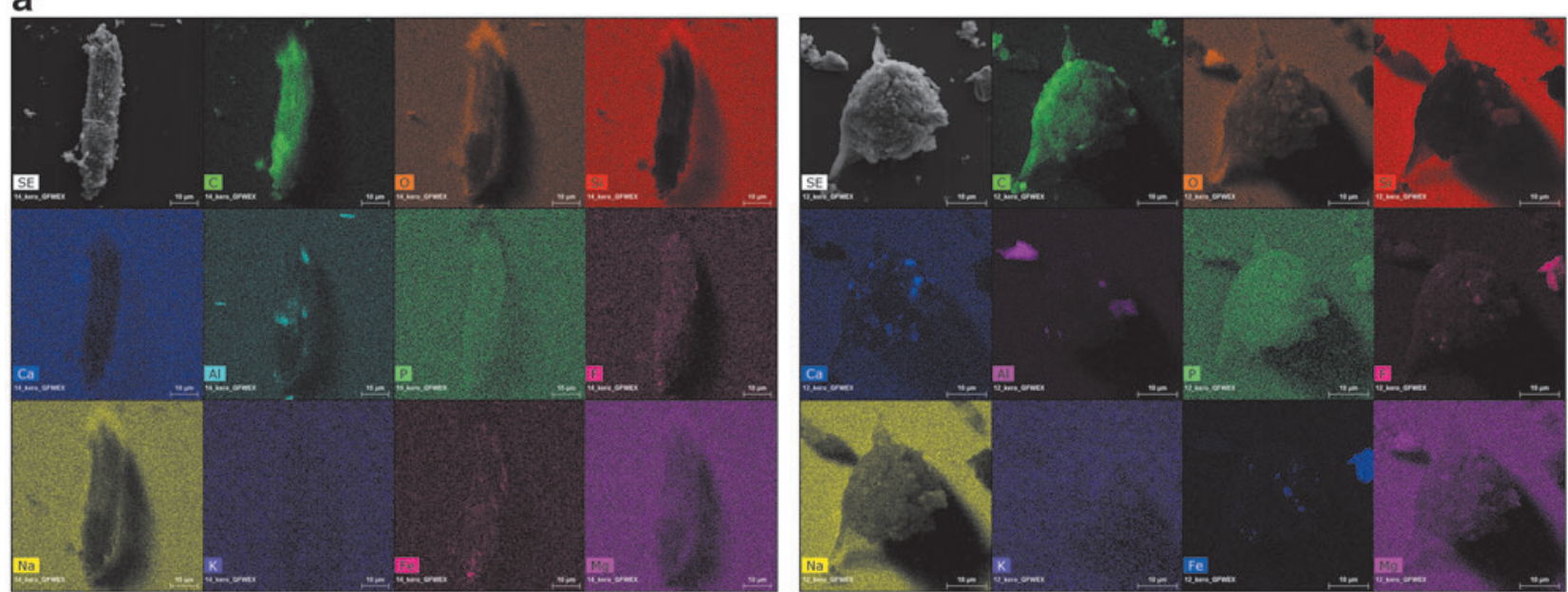

b
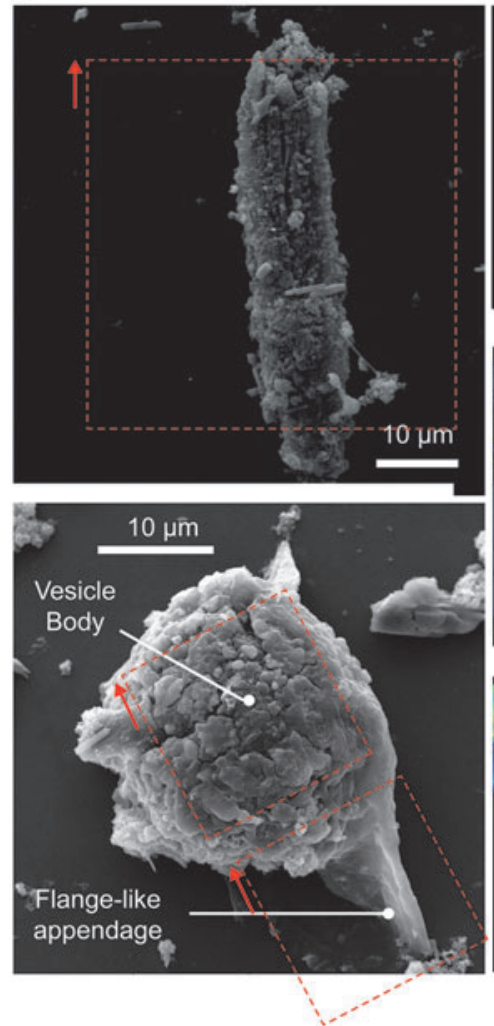

$10^{3} \mathrm{Cts} / \mathrm{s}$
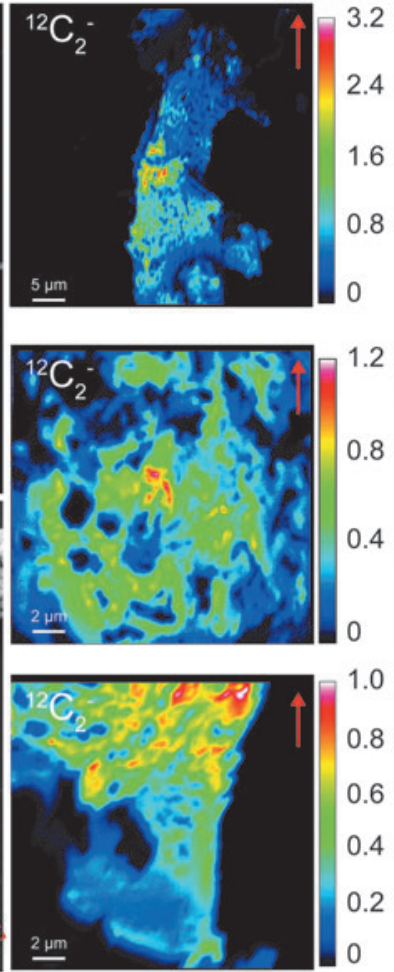

$10^{3} \mathrm{Cts} / \mathrm{s}$
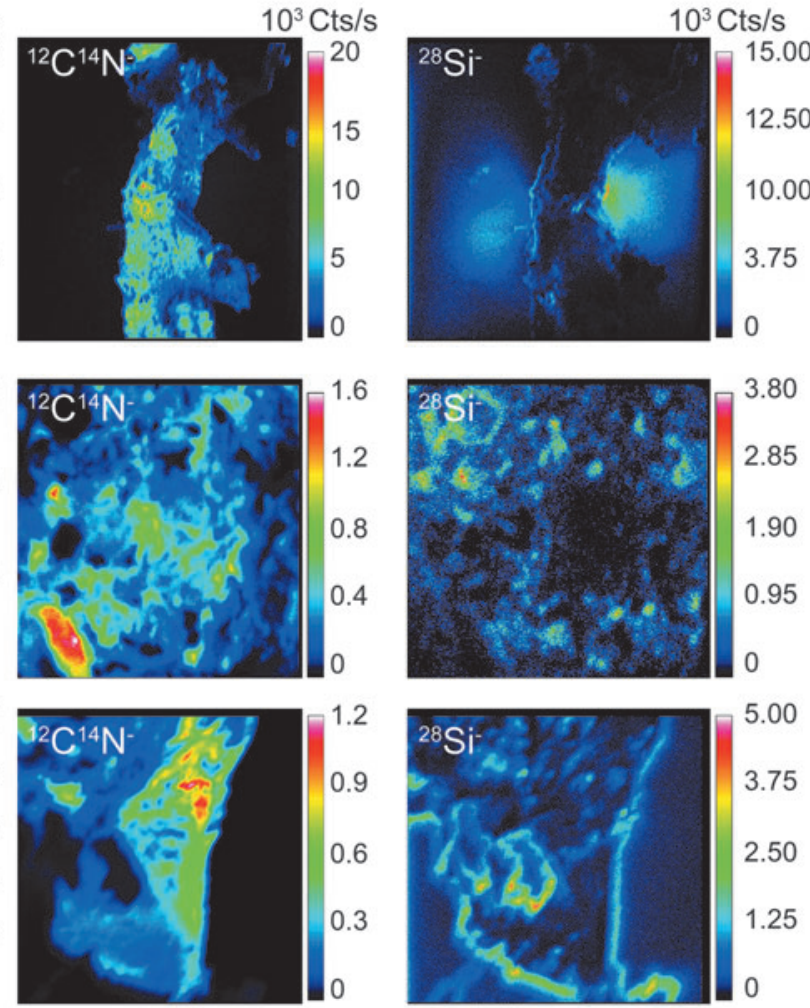

FIG. 3. (a) Secondary electron and X-ray images of selected elements for a film-like and a well-preserved lenticular-like isolated microfossil. (b) NanoSIMS ion images $\left({ }^{12} \mathrm{C}_{2}^{-},{ }^{12} \mathrm{C}^{14} \mathrm{~N}^{-}\right.$, and $\left.{ }^{28} \mathrm{Si}^{-}\right)$determined on the filament-like microfossil and on the two distinct ultrastructures of the well-preserved lenticular-like microfossil, namely the vesicle body and the flangelike appendage. 


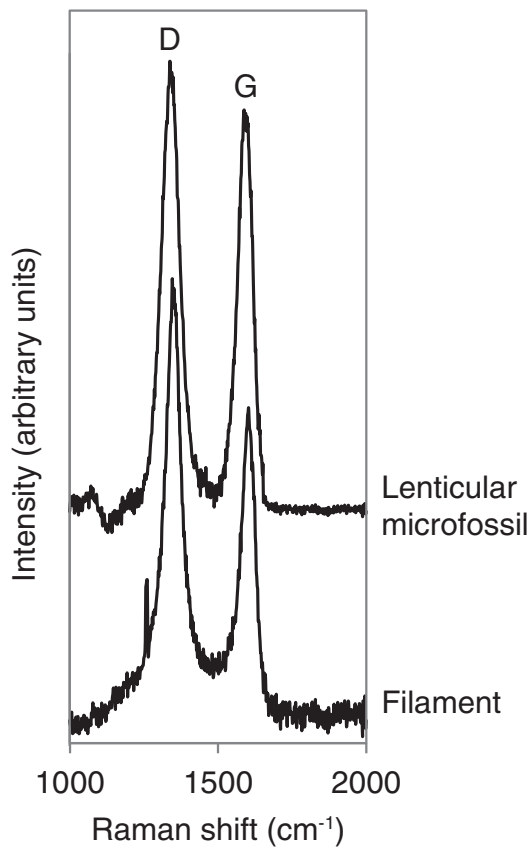

FIG. 4. First-order Raman spectrum of the filament and the lenticular microfossil presented in Fig. 3.

proxy of the N/C atomic ratio for silica-free kerogens or pure organic standards (Thomen et al., 2014; Alleon et al., 2015). However, in the case of microfossils, two additional analytical artifacts should be considered as follows: (1) matrix effects (chemical heterogeneity) linked to the occurrence of silicate minerals and (2) microtopographic effects yielding a difference in the emissivity of the ${ }^{12} \mathrm{C}_{2}{ }^{-}$and ${ }^{12} \mathrm{C}^{14} \mathrm{~N}^{-}$ions. Owing to the imaging capability of the NanoSIMS, the ${ }^{12} \mathrm{C}_{2}$ and ${ }^{12} \mathrm{C}^{14} \mathrm{~N}^{-}$variations have been recorded at a high spatial resolution. In the following, we demonstrate that the spatial variation between ${ }^{12} \mathrm{C}_{2}^{-}$and ${ }^{12} \mathrm{C}^{14} \mathrm{~N}^{-}$is linear and that its corresponding slope $\alpha$ is correlated with the N/C atomic ratio. However, this linear variation between ${ }^{12} \mathrm{C}_{2}-$ and ${ }^{12} \mathrm{C}^{14} \mathrm{~N}^{-}$ shows a nonzero intercept $\beta$, possibly related to the sample surface microtopography. No relation was found between $\beta$ and $\alpha$, justifying in turn the use of $\alpha$ to record the relative variations of the $\mathrm{N} / \mathrm{C}$ ratio. In addition, no measurable variation in the emissivity of the ${ }^{12} \mathrm{C}_{2}{ }^{-}$and ${ }^{12} \mathrm{C}^{14} \mathrm{~N}^{-}$ions has been detected in the presence of silicate minerals, avoiding measurable matrix effects on $\alpha$.

3.2.1. The slope $\alpha$, a record of the $\mathrm{N} / \mathrm{C}$ atomic ratio. Emissions of ${ }^{12} \mathrm{C}_{2}^{-}$and ${ }^{12} \mathrm{C}^{14} \mathrm{~N}^{-}$in resin, tryptophan, and a type III kerogen are systematically correlated (Fig. 5a, 5b; Table 1). Although both emissions converge toward 0 for lower ion counting rates, the linear regression calculated on the whole range of emissions yields a nonzero intercept $\beta$. This relationship is characterized by a slope $\alpha$. In Fig. $5 \mathrm{c}$, the slopes of pure kerogen and standards are reported versus bulk N/C atomic ratio. Note that for a $\mathrm{N}$-free sample (polycarbonate filter) no relationship between the emissions of the ${ }^{12} \mathrm{C}_{2}{ }^{-}$and ${ }^{12} \mathrm{C}^{14} \mathrm{~N}^{-}$ions is found (Table 1). Hence, a significantly linear relationship between the ${ }^{12} \mathrm{C}_{2}-$ and ${ }^{12} \mathrm{C}^{14} \mathrm{~N}^{-}$ion emissions is the preliminary condition to consider in order to define a slope $\alpha$ that can be used to record the N/C atomic ratio.
3.2.2. Matrix effect. Oehler et al. (2009) defined a matrix effect in their NanoSIMS measurements as the enhancement of the ${ }^{28} \mathrm{Si}^{-}$and ${ }^{16} \mathrm{O}^{-}$ion emissions when these ions are closely and spatially associated with carbon. Such a matrix effect may be linked to a higher conductibility of $\mathrm{Si}$ associated with carbonaceous globules compared to that of $\mathrm{Si}$ in the surrounding siliceous minerals. In microfossils from chert thick section (Fig. 6a), no relationship between ${ }^{28} \mathrm{Si}^{-}$on the one hand and ${ }^{12} \mathrm{C}_{2}^{-}$(Fig. 6b) and ${ }^{12} \mathrm{C}^{14} \mathrm{~N}^{-}$ (Fig. 6c) ion emissions on the other hand has been found. Hence, $\alpha$ is not affected by the occurrence of Si.

3.2.3. Microtopography. To investigate the effect of microtopography, we compared the ${ }^{12} \mathrm{C}_{2}{ }^{-}$and ${ }^{12} \mathrm{C}^{14} \mathrm{~N}^{-}$ion emissions on two selected flat and nonflat (microtopographic features between 1 and $10 \mu \mathrm{m}$ ) areas from a chemically homogeneous resin standard (Fig. 7a). In Fig. 7, it can be seen that microtopography does not cause measurable shift in $\alpha$ (Fig. 7b; flat area: $\alpha=0.52 \pm 0.05$; nonflat area: $\alpha=0.56 \pm 0.02)$.

Figure $7 \mathrm{c}$ shows that the value of the ${ }^{12} \mathrm{C}^{14} \mathrm{~N}^{-} /{ }^{12} \mathrm{C}_{2}^{-}$ratio is not affected by small micrometric scale microtopography up to $2 \mu \mathrm{m}$. Although a $10 \mu \mathrm{m}$ of topography can enhance the ionic ${ }^{12} \mathrm{C}^{14} \mathrm{~N}^{-} /{ }^{12} \mathrm{C}_{2}^{-}$ratio by a factor of up to 4 , the slope of the correlated variations between ${ }^{12} \mathrm{C}^{14} \mathrm{~N}^{-}$and ${ }^{12} \mathrm{C}_{2}^{-}$is only related to the N/C atomic ratio of the sample. Such a bias in the determination of the ${ }^{12} \mathrm{C}^{14} \mathrm{~N}^{-} /{ }^{12} \mathrm{C}_{2}^{-}$ratio is also related to the value of the nonzero intercept $\beta$, which seems to rise through enhanced microtopography (Fig. 7b, 7c). In contrast to the ${ }^{12} \mathrm{C}^{14} \mathrm{~N}^{-} /{ }^{12} \mathrm{C}_{2}^{-}$ratio, the slope $\alpha$ is constant in topographic domain covering $1-10 \mu \mathrm{m}$ (Fig. 7c). Note that due to the size of the presently studied microfossils and the fact that microfossil edges were not considered, the microtopographic features cannot exceed a few micrometers.

Consequently, the matrix and microtopographic effects do not bias the use of the slope $\alpha$, as a record of the N/C atomic ratio.

\section{Discussion}

Evidence for the permineralization of a part of the microfossils from the Farrel Quartzite was previously suggested by Oehler et al. (2009) owing to the co-emissions of the $\mathrm{Si}^{-}, \mathrm{C}_{2}^{-}$, and $\mathrm{CN}^{-}$ions in microfossils from thin section. Here, ${ }^{28} \mathrm{Si}^{-}$and ${ }^{12} \mathrm{C}_{2}^{-}$ions on the one hand and ${ }^{28} \mathrm{Si}^{-}$and ${ }^{12} \mathrm{C}^{14} \mathrm{~N}^{-}$ions on the other hand were not spatially associated at the pixel scale (Fig. 6). Such findings may echo results observed in the 3.4 Ga Strelley Pool Formation, in which Lepot et al. (2013) observed lenticular microfossils composed of carbonaceous globules that were interpreted as degradation by-products of Archean microorganisms. However, in the present study, no 3-D carbonaceous globules were observed in the isolated kerogen. Since they did not survive the acid treatment, they must not be considered encapsulated but rather permineralized.

In contrast to carbonaceous globules, carbonaceous microfossils were recovered in the acid maceration residue. Among these microfossils, one example of an exceptional morphological preservation of a lenticular microfossil is shown. Classically, in the literature, lenticular microfossils exhibit two kinds of flange-like appendages situated either in the equatorial plane or at the apical part of the vesicle 
a
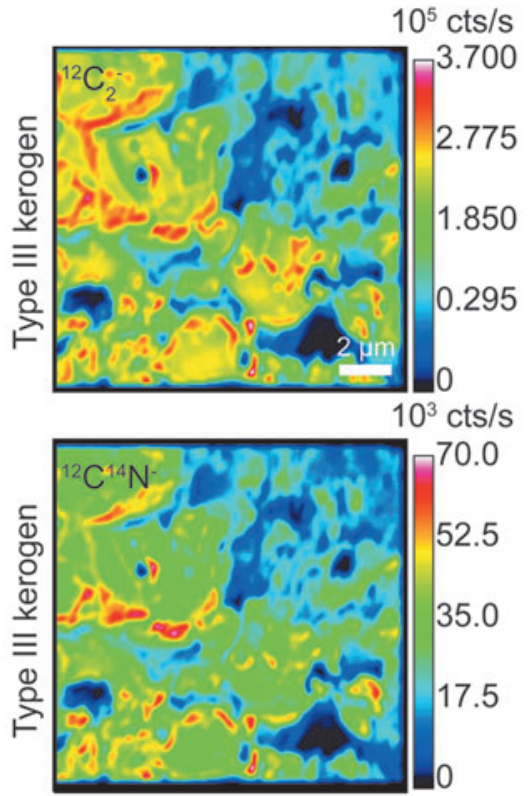

b

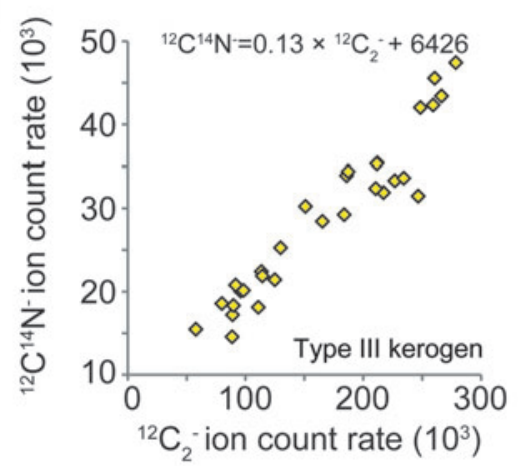

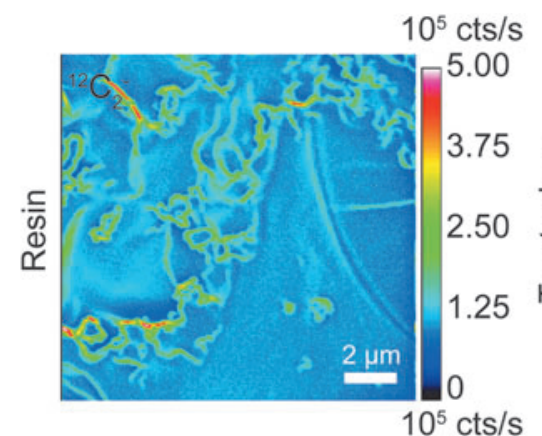
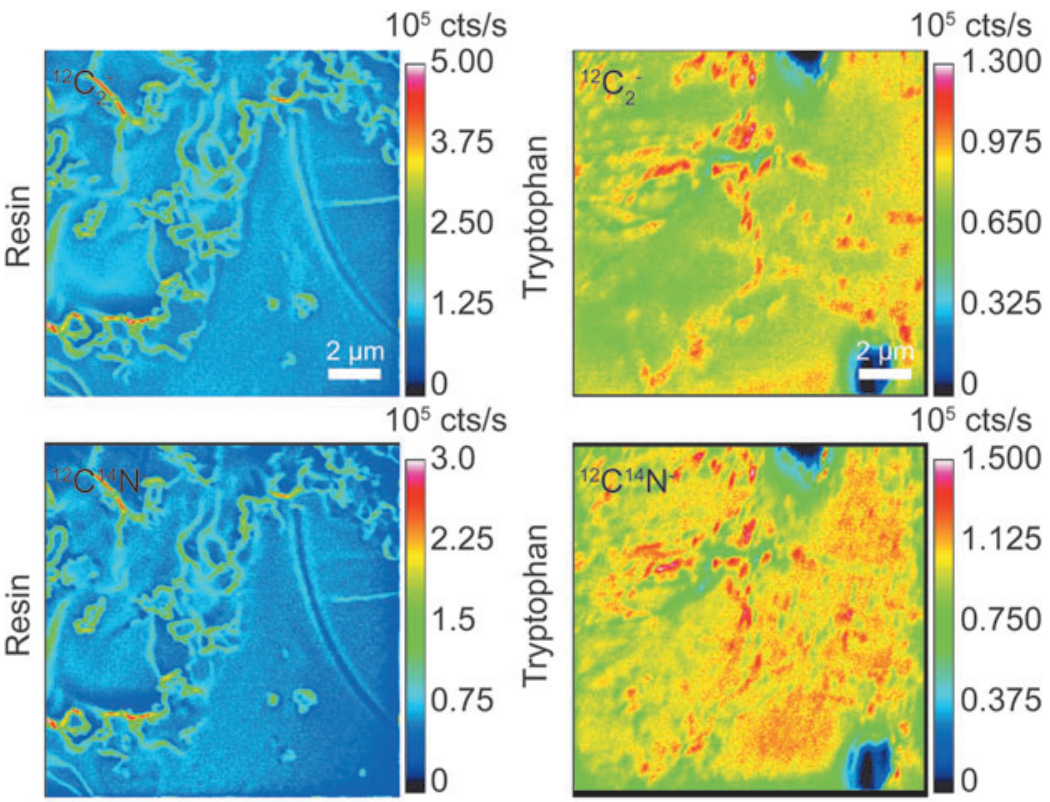

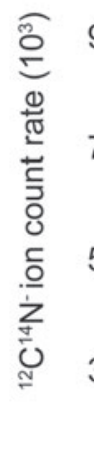

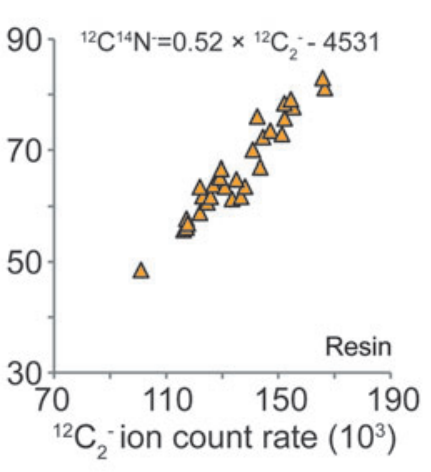

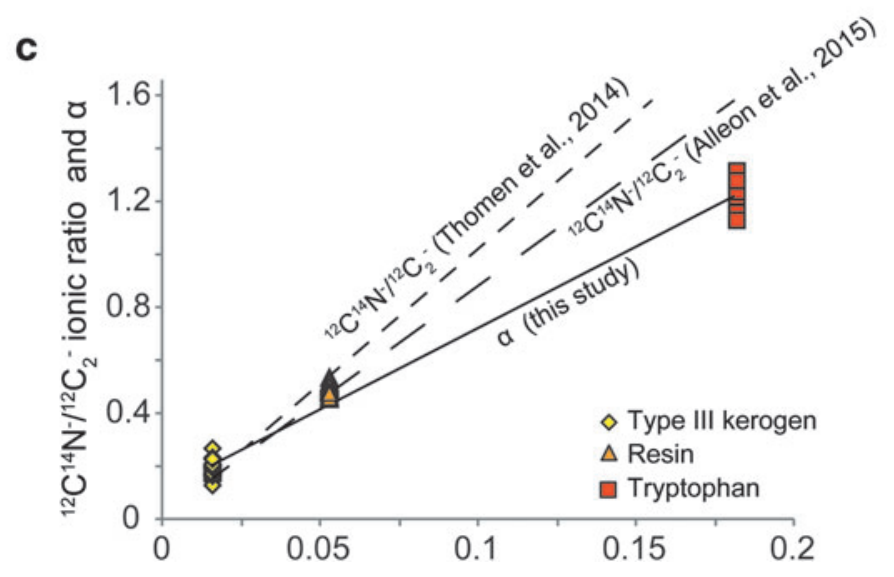

FIG. 5. (a) NanoSIMS ion images $\left({ }^{12} \mathrm{C}_{2}{ }^{-}\right.$and $\left.{ }^{12} \mathrm{C}^{14} \mathrm{~N}^{-}\right)$of type III kerogen, resin, and tryptophan. (b) Relationship between the emissions of ${ }^{12} \mathrm{C}_{2}^{-}$and ${ }^{12} \mathrm{C}^{14} \mathrm{~N}^{-}$ions in each standard. Each point is related to a ROI $(n=30)$ manually drawn on the flattest part of the standards following the procedure described in Alleon et al. (2015; see Table 1 for further information about the number and size of ROIs). (c) Determination of the N/C atomic ratio by the use of the ${ }^{12} \mathrm{C}^{14} \mathrm{~N}^{-12} \mathrm{C}_{2}^{-}$ionic ratio (Thomen et al., 2014; Alleon et al., 2015) and the slope $\alpha$. Note that coal and microfossils (session 1) were not studied in the same analytical session as the three standards (session 2) used to calibrate the use of the slope $\alpha$ as a proxy of the N/C atomic ratio. Accordingly, this prevents any calculation of in situ N/C atomic ratios of microfossils. Also, note the linear relationship in each case, which evidences the absence of matrix effect on the determination of both ${ }^{12} \mathrm{C}^{14} \mathrm{~N}^{-12} \mathrm{C}_{2}^{-}$ionic ratio and the slope $\alpha$. 
Table 1. Bulk N/C Atomic Ratio (Thomen et al., 2014; Alleon et al., 2015) of Studied Standards, Number and Size of Regions of Interest (ROIs) Used (I) to Test the Correlation BetweEn the EMISSIONS of the ${ }^{12} \mathrm{C}_{2}^{-}$AND ${ }^{12} \mathrm{C}^{14} \mathrm{~N}^{-}$Ions by Using Spearman's Rank Correlation and (II) to Determine THE SLOPE $\alpha$ ON STANDARDS

\begin{tabular}{|c|c|c|c|c|c|c|}
\hline Purpose & Sample & $\begin{array}{c}\text { Bulk N/C } \\
\text { atomic ratio }\end{array}$ & $\begin{array}{l}\text { Number } \\
\text { of ROIs }\end{array}$ & $\begin{array}{c}\text { ROIs } \\
\text { diameter }(\mu m)\end{array}$ & $\begin{array}{l}\text { Spearman } \\
\text { p value }\end{array}$ & $\alpha \pm 1 \sigma_{r e g}$ \\
\hline Blank & Polycarbonate filter & - & 30 & 1.5 & 0.50 & - \\
\hline \multirow{3}{*}{ Calibration line } & Type III kerogen & 0.016 & 30 & 1.5 & $<0.0001$ & $0.13 \pm 0.01$ \\
\hline & Resin & 0.053 & 30 & 0.8 & $<0.0001$ & $0.52 \pm 0.05$ \\
\hline & Tryptophan & 0.182 & 30 & 1.5 & $<0.0001$ & $1.20 \pm 0.13$ \\
\hline \multirow[t]{7}{*}{ External reproducibility } & Coal 1 & 0.0022 & 545 & 1.1 & $<0.0001$ & $0.11 \pm 0.004$ \\
\hline & Coal 2 & 0.0022 & 460 & 1.1 & $<0.0001$ & $0.10 \pm 0.002$ \\
\hline & Coal 3 & 0.0022 & 457 & 1.3 & $<0.0001$ & $0.09 \pm 0.002$ \\
\hline & Coal 4 & 0.0022 & 478 & 1.3 & $<0.0001$ & $0.09 \pm 0.004$ \\
\hline & Coal 5 & 0.0022 & 321 & 1.3 & $<0.0001$ & $0.13 \pm 0.003$ \\
\hline & Coal 6 & 0.0022 & 365 & 1.3 & $<0.0001$ & $0.09 \pm 0.002$ \\
\hline & Coal 7 & 0.0022 & 367 & 1.4 & $<0.0001$ & $0.08 \pm 0.004$ \\
\hline
\end{tabular}

To minimize the effect of microtopography, ROIs were selected in the flattest part of the standard as recommended by Alleon et al. (2015). In the specific case of the coal standard, our purpose was to measure the external reproducibility. Thus, a maximum of ROIs were selected to characterize the strict effect of analytical drift, avoiding then to take into account twice the effect of microtopography during the analyses of microfossils. Note that the polycarbonate filter was used as a nitrogen blank in which the ${ }^{12} \mathrm{C}_{2}^{-}$and ${ }^{12} \mathrm{C}^{14} \mathrm{~N}^{-}$ion emissions are not significantly correlated.

body (Sugitani et al., 2009; House et al., 2013). Here, the flange-like appendage was situated at the apical part of the vesicle body. Lenticular, but also film-like, microfossils consist almost entirely of organic matter, suggesting that they are organic-walled microfossils removed from the sil- ica matrix by the HF treatment. In turn, this result implies the preservation of some organic-walled microfossils by encapsulation rather than by permineralization. These organic-walled microfossils are characterized by equivalent Raman line shape (Fig. 4), corresponding to advanced
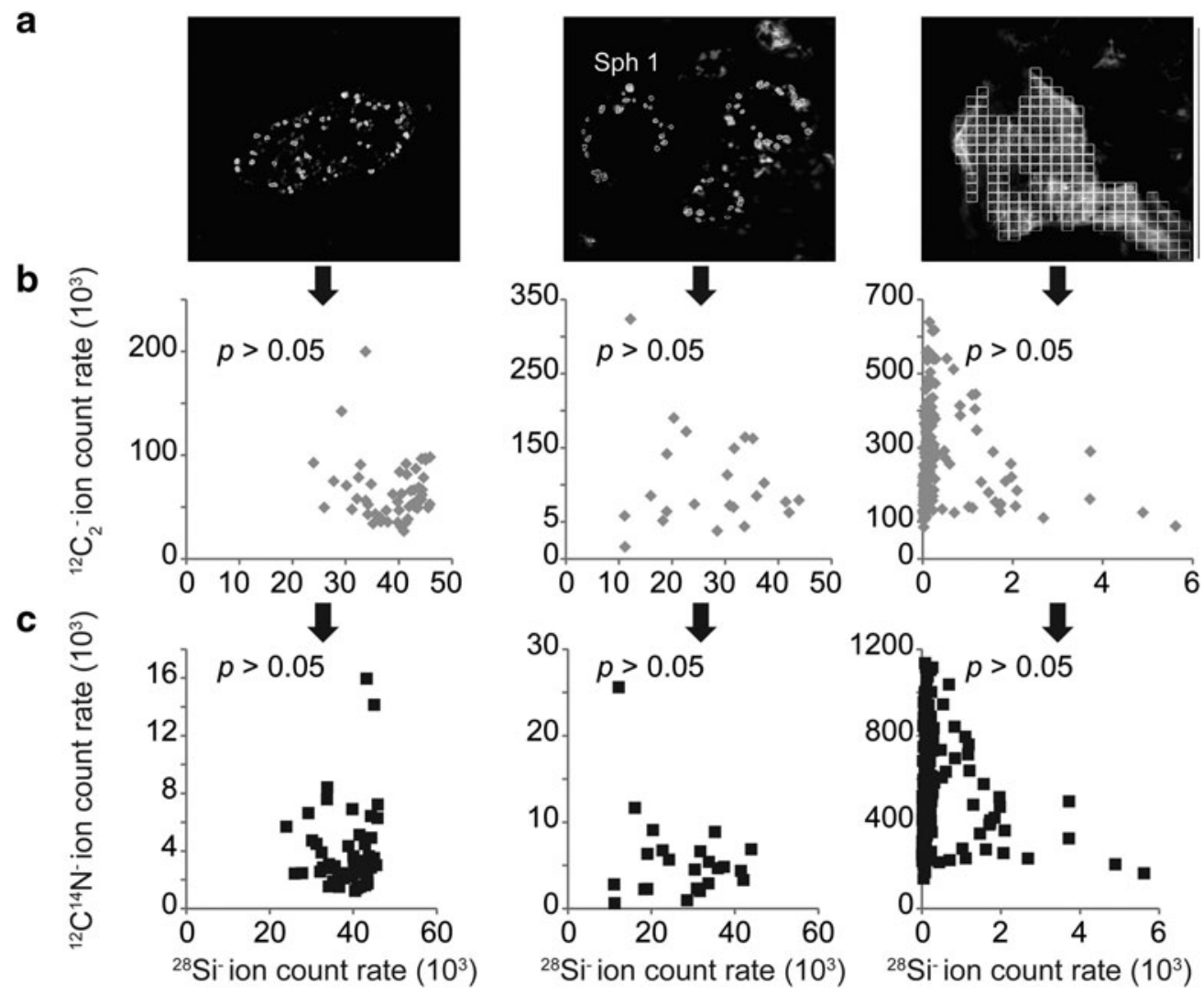

FIG. 6. (a) NanoSIMS images $\left({ }^{12} \mathrm{C}_{2}{ }^{-}\right)$of microfossils from thick section (presented in Fig. 2) displaying the ROIs used to study the potential relationship between (b) the ${ }^{28} \mathrm{Si}^{-}$and the ${ }^{12} \mathrm{C}_{2}^{-}$ions and (c) the ${ }^{28} \mathrm{Si}^{-}$and the ${ }^{12} \mathrm{C}^{4} \mathrm{~N}^{-}$ions. In order to constrain the spatial variability of the emissions of the ${ }^{12} \mathrm{C}_{2}^{-}$and ${ }^{12} \mathrm{C}^{14} \mathrm{~N}^{-}$ions, ROIs were manually drawn around carbon/ silica in permineralized microfossils. For encapsulated microfossils, a grid was used (see Table 1 for further information on the number and the size of the ROIs). 
a
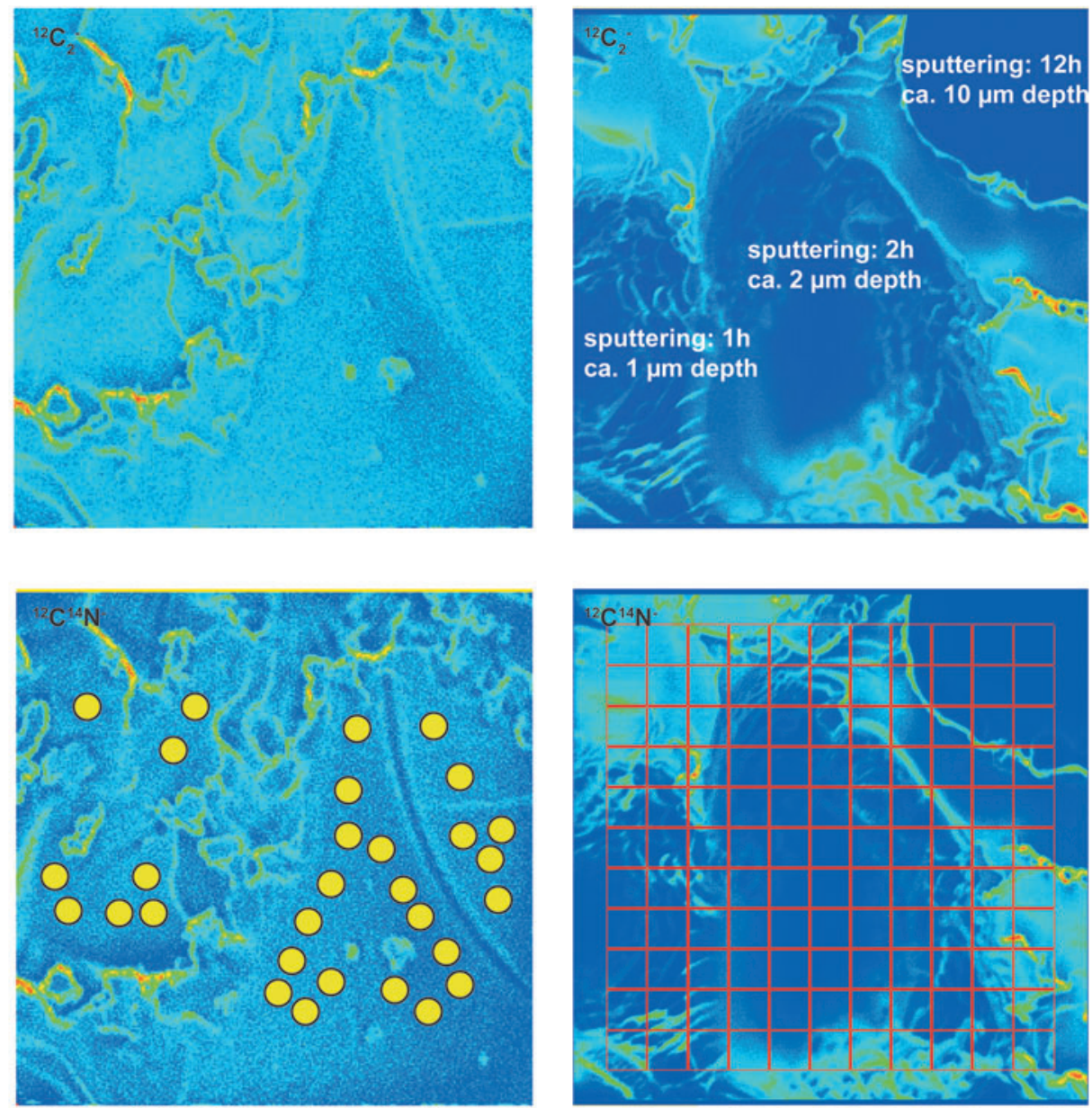

b

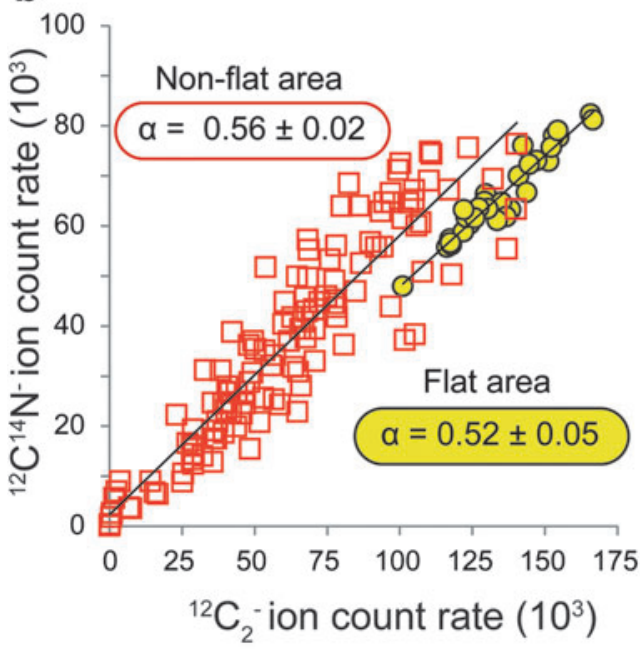

C

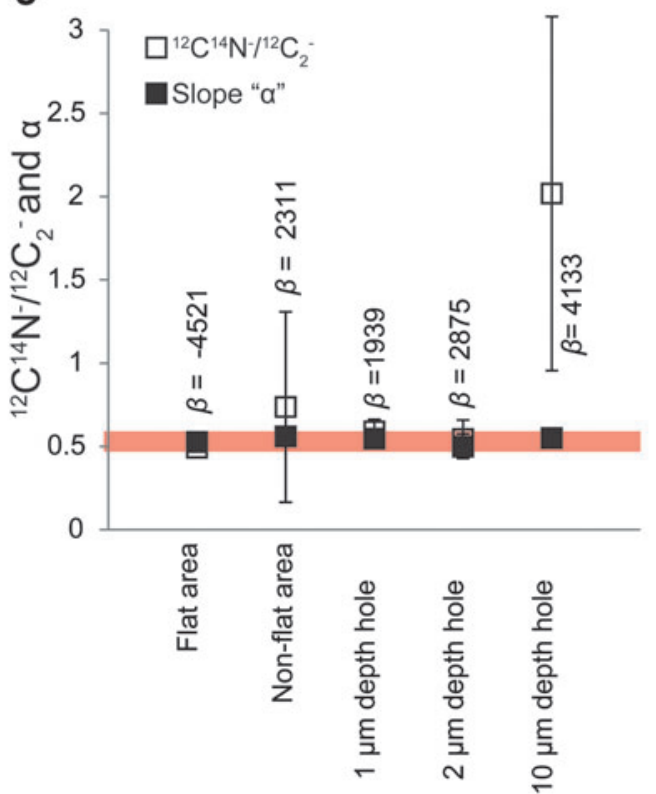

FIG. 7. Investigation of the effect of microtopography on the determination of the slope $\alpha$ and its error on $(\mathbf{a}){ }^{12} \mathrm{C}_{2}{ }^{-}$and ${ }^{12} \mathrm{C}^{14} \mathrm{~N}^{-}$ ion flat (left images) and nonflat (right images) areas from the resin standards. In the nonflat area, photonic microtopography was created through extensive sputtering $(1,2$, and $12 \mathrm{~h})$, leading to the creation of micrometric-scale microtopography estimated through microscopy (ca. 1, 2, and $10 \mu \mathrm{m}$ depth, respectively). The relationship between the emissions of ${ }^{12} \mathrm{C}_{2}^{-}$and ${ }^{12} \mathrm{C}^{14} \mathrm{~N}^{-}$ions was estimated on the above (i) flat area using 30 ROIs (yellow circles of $0.8 \mu \mathrm{m}$ diameter) as suggested by Alleon et al. (2015) and (ii) nonflat area using 121 ROIs (red grid, each square has a width of $2.2 \mu \mathrm{m}$ ). (b) Relationships between the emissions of ${ }^{12} \mathrm{C}_{2}{ }^{-}$and ${ }^{12} \mathrm{C}^{14} \mathrm{~N}^{-}$ions in the flat and the nonflat areas. (c) Comparison between the ${ }^{12} \mathrm{C}^{14} \mathrm{~N}^{-} /{ }^{12} \mathrm{C}_{2}^{-}$ionic ratio calculated as in Alleon et al. (2015) and the slope $\alpha$ (this study) values across microscale microtopography. The red area indicates the values of the slope $\alpha$ determined on the flat area. The intercept of the linear regression between the emissions of ${ }^{12} \mathrm{C}_{2}{ }^{-}$and ${ }^{12} \mathrm{C}^{14} \mathrm{~N}^{-}$ions is noted $\beta$. 
a Fig. 2a: Lenticular microfossil

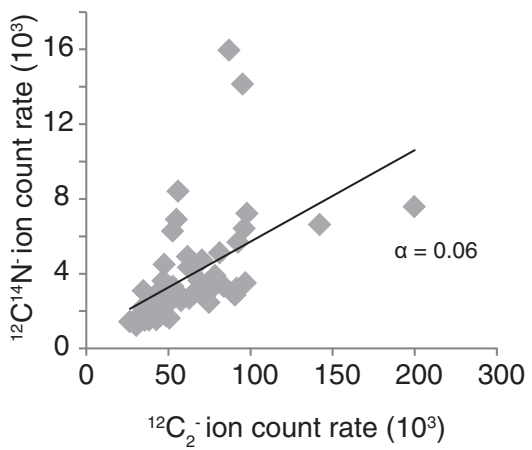

b

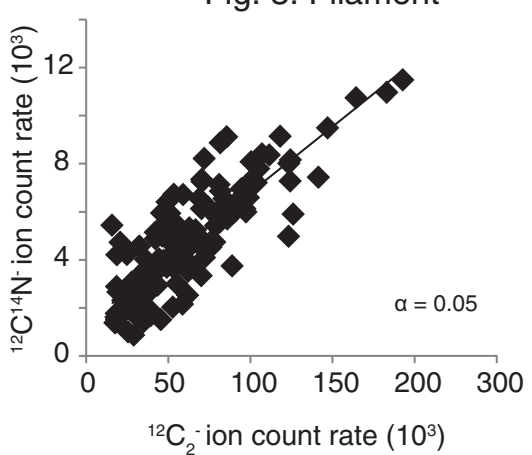

Fig. 2b: Spheroid $n^{\circ} 1$

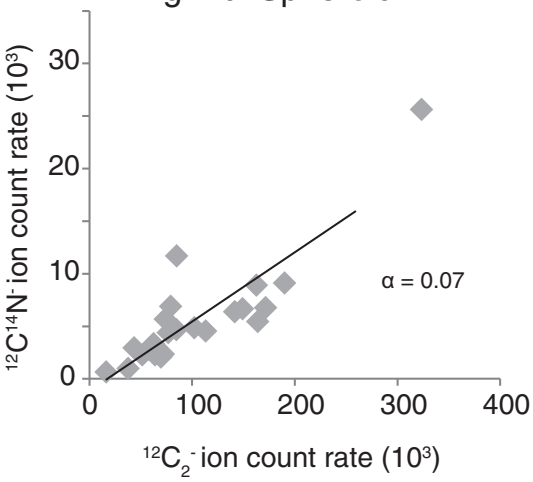

Fig. 3: Vesicle Body

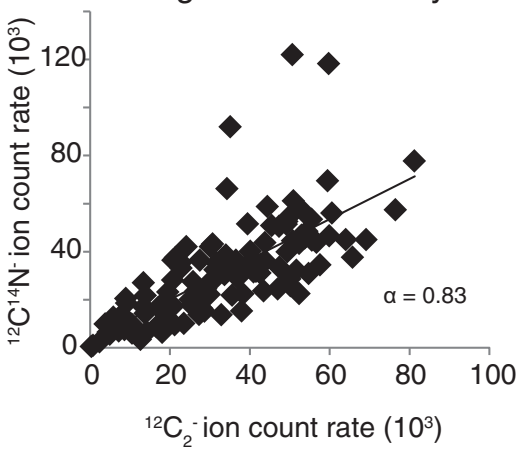

Fig. 2c: Film

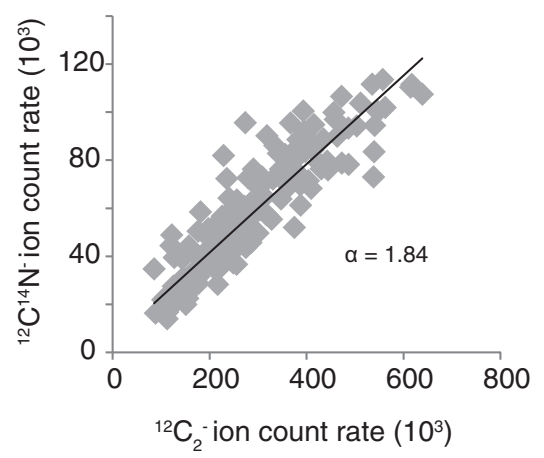

Fig. 3: Flange

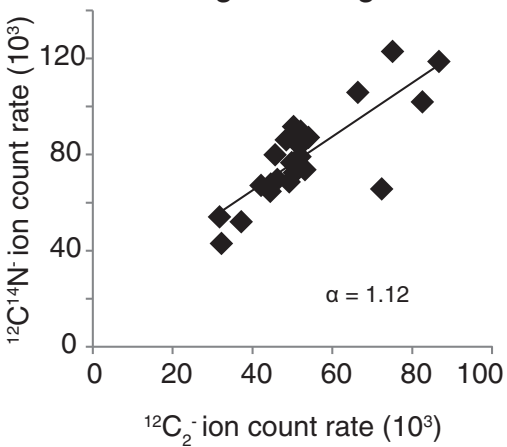

FIG. 8. (a) Relationships between the emissions of ${ }^{12} \mathrm{C}_{2}-$ and ${ }^{12} \mathrm{C}^{14} \mathrm{~N}^{-}$ions in microfossils from thin section. (b) Relationship between the emissions of ${ }^{12} \mathrm{C}_{2}^{-}$and ${ }^{12} \mathrm{C}^{14} \mathrm{~N}^{-}$ions in encapsulated microfossils from the kerogen residue.

carbonization/greenschist facies metamorphism in silicified cherts (Delarue et al., 2016). Raman characteristics of the microfossils are then consistent with the thermal history of the Farrel Quartzite cherts (Sugitani et al., 2007), revealing, in turn, their syngenicity.

The slope $\alpha$ parameter for both permineralized and encapsulated microfossils was calculated as a proxy of the in situ N/C atomic ratio (Fig. 8; Table 2). The correlation between ${ }^{12} \mathrm{C}_{2}^{-}$and ${ }^{12} \mathrm{C}^{14} \mathrm{~N}^{-}$is statistically significant for 11 out of the 14 analyzed microfossils (Table 2), which will be considered in the following discussion.

In the permineralized lenticular and spheroid microfossils, $\alpha$ ranges from 0.03 to 0.19 , whereas it ranges from 0.05 to 1.84 in the encapsulated lenticular and film-like ones (Table 2). First

Table 2. Number and Diameter of ROIs Used on Studied Microfossils

\begin{tabular}{|c|c|c|c|c|c|c|}
\hline Microfossil type & $\begin{array}{c}\text { Thin section } \\
(T S) \text { vs. kerogen }(K)\end{array}$ & $\begin{array}{c}\text { Encapsulated }(E) \\
\text { vs. permineralized }(P)\end{array}$ & $\begin{array}{l}\text { Number } \\
\text { of ROIs }\end{array}$ & $\begin{array}{l}\text { ROI diameter } \\
\quad(\mu m \pm S D)\end{array}$ & $\begin{array}{l}\text { Spearman } \\
\text { p value }\end{array}$ & $\alpha \pm 1 \sigma_{t o t}$ \\
\hline Lenticular & TS & $\mathrm{P}$ & 25 & $0.63 \pm 0.15$ & 0.0013 & $0.19 \pm 0.05$ \\
\hline Lenticular $^{\mathrm{a}, \mathrm{c}}$ & $\mathrm{TS}$ & $\mathrm{P}$ & 49 & $0.66 \pm 0.12$ & $<0.0001$ & $0.06 \pm 0.01$ \\
\hline Lenticular & $\mathrm{TS}$ & $\mathrm{P}$ & 42 & $0.78 \pm 0.20$ & 0.0002 & $0.07 \pm 0.02$ \\
\hline Spheroid & TS & $\mathrm{P}$ & 52 & $0.66 \pm 0.11$ & $<0.0001$ & $0.03 \pm 0.01$ \\
\hline Spheroid & TS & $\mathrm{P}$ & 25 & $0.65 \pm 0.40$ & 0.14 & - \\
\hline Spheroid $1^{\mathrm{a}, \mathrm{c}}$ & $\mathrm{TS}$ & $\mathrm{P}$ & 23 & $0.94 \pm 0.27$ & $<0.0001$ & $0.07 \pm 0.01$ \\
\hline Spheroid 2 & $\mathrm{TS}$ & $\mathrm{P}$ & 20 & $1.08 \pm 0.52$ & 0.01 & $0.11 \pm 0.05$ \\
\hline Spheroid 3 & TS & $\mathrm{P}$ & 13 & $0.70 \pm 0.38$ & 0.11 & - \\
\hline Film & TS & $\mathrm{E}$ & 252 & 2.9 & $<0.0001$ & $1.48 \pm 0.13$ \\
\hline Filament $^{\mathrm{b}, \mathrm{c}}$ & $\mathrm{K}$ & $\mathrm{E}$ & 146 & 2.4 & $<0.0001$ & $0.05 \pm 0.00$ \\
\hline Film & $\mathrm{K}$ & $\mathrm{E}$ & 45 & 1.3 & 0.11 & - \\
\hline Film ${ }^{\mathrm{a}, \mathrm{c}}$ & $\mathrm{TS}$ & $\mathrm{E}$ & 195 & 2.2 & $<0.0001$ & $1.84 \pm 0.14$ \\
\hline Lenticular (vesicle) $)^{\mathrm{b}, \mathrm{c}}$ & $\mathrm{K}$ & $\mathrm{E}$ & 121 & 1.2 & $<0.0001$ & $0.83 \pm 0.09$ \\
\hline Lenticular (flange) & $\mathrm{K}$ & $\mathrm{E}$ & 28 & 0.7 & $<0.0001$ & $1.12 \pm 0.18$ \\
\hline
\end{tabular}

Spearman's rank correlation, slope $\alpha$ and associated error $\left(1 \sigma_{\text {tot }}\right)$ determined through the linear relationship between the emissions of the ${ }^{12} \mathrm{C}_{\mathrm{a}, \mathrm{b}, \mathrm{c}}^{-}$and ${ }^{12} \mathrm{C}^{14} \mathrm{~N}^{-}$ions in both permineralized and encapsulated microfossils from thin section and kerogen.

${ }^{, b, c}$ Microfossils presented in Figs. 2, 3, and 8 are indicated by the superscript a, b, and c, respectively. 
of all, these data suggest that there is an unexpected geochemical heterogeneity among the microfossils preserved in the 3.0 Ga Farrel Quartzite. Most of the encapsulated microfossils are characterized by a greater $\alpha$ compared to permineralized ones (Fig. 8; Table 2). This indicates that encapsulated microfossils present a higher geochemical preservation level than the permineralized ones and that the mode of fossilization may be a key controlling factor in the geochemical heterogeneity in the Farrel Quartzite carbonaceous matter. Finally, this difference in the extent of geochemical preservation between permineralized and encapsulated microfossils is consistent with observations made on modern microbial mats that show that microorganisms are better preserved through encapsulation (Konhauser and Ferris, 1996). Focusing future studies on Archean encapsulated microfossils may then provide the best geochemical evidence in the search for traces of early life.

\section{Conclusion}

In this study, we provide new lines of evidence that support the partial fossilization of carbonaceous microfossils through encapsulation in the $c a$. 3.0 Ga cherts from the Farrel Quartzite in the Pilbara Craton, Western Australia. Encapsulated microfossils were observed both in the thin section and in the kerogen fraction. Using the slope $\alpha$ parameter relating the ${ }^{12} \mathrm{C}_{2}^{-}$and ${ }^{12} \mathrm{C}^{14} \mathrm{~N}^{-}$NanoSIMS emissions as an index of geochemical preservation of the studied microfossils, we demonstrate that encapsulated microfossils present a higher level of geochemical preservation than permineralized ones. Thus, the mechanism of fossilization of microorganisms may be considered as a key controlling factor in preserving geochemical heterogeneity.

Overall, our results suggest that focusing in situ investigations on well-preserved encapsulated carbonaceous matter may provide the best chance to recover information on the earliest forms of terrestrial life that are likely to be lost in bulk investigations.

\section{Acknowledgments}

The authors are thankful to J.J. Pantel for his help in sample crushing. The authors are also grateful to A. Gonzalez-Cano and S. Mostefaoui for elemental measurements at the National NanoSIMS Facility of the MNHN, to S. Bernard for providing NanoSIMS standards, to S. Pont for microfossil imaging at the SEM Facility of the MNHN. The authors are also grateful to V. Rouchon and O. Belhadj (Center for Research on the Preservation of Collections, USR 3224). This work was supported by the ERC project "PaleoNanoLife" and by the Japanese Society for the Promotion of Science (a grant-in-aid No. 24654162). Special thanks to Tsutomu Nagaoka (Nagoya University) for assistance in preparation of thin section and to Dr. K. Grey (Western Australia) for permission for sample export.

\section{Disclosure Statement}

No competing financial interests exist.

\section{References}

Alleon, J., Bernard, S., Remusat, L., and Robert, F. (2015) Estimation of nitrogen-to-carbon ratios of organics and carbon materials at the submicrometer scale. Carbon 84:290-298.
Alleon, J., Bernard, S., Le Guillou, C., Marin-Carbonne, J., Pont, S., Beyssac, O., McKeegan, K.D., and Robert, F. (2016) Molecular preservation of 1.88 -Ga Gunflint organic microfossils as a function of temperature and mineralogy. Nat Commun 7, doi:10.1038/ncomms11977.

Beaumont, V. and Robert, F. (1999) Nitrogen isotope ratios of kerogens in Precambrian cherts: a record of the evolution of atmosphere chemistry? Precambrian Res 96:63-82.

Delarue, F., Rouzaud, J-N., Derenne, S., Bourbin, M., Westall, F., Kremer, B., Sugitani, S., Deldicque, D., and Robert, F. (2016) The Raman-derived carbonization continuum: a tool to select the best preserved molecular structures in Archean kerogens. Astrobiology 16:407-417.

Derenne, S., Robert, F., Skrzypczak-Bonduelle, A., Gourier, D., Binet, L., and Rouzaud, J.-N. (2008) Molecular evidence for life in the 3.5 billion year old Warrawoona chert. Earth Planet Sci Lett 272:476-480.

Grey, K. and Sugitani, K. (2009) Palynology of Archean microfossils (c. $3.0 \mathrm{Ga}$ ) from the Mount Grant area, Pilbara Craton, Western Australia: further evidence of biogenicity. Precambrian Res 173:60-69.

House, C.H., Oehler, D.Z., Sugitani, K., and Mimura, K. (2013) Carbon isotopic analyses of $c a$. 3.0 Ga microstructures imply planktonic autotrophs inhabited Earth's early oceans. Geology 41:651-654.

Javaux, E.J., Marshall, C.P., and Bekker, A. (2010) Organicwalled microfossils in 3.2-billion-year-old shallow-marine siliciclastic deposits. Nature 463:934-938.

Konhauser, K.O. and Ferris, F.G. (1996) Diversity of iron and silica precipitation by microbial mats hydrothermal waters, Iceland: implications for Precambrian iron formations. Geology 24:323-326.

Lepot, K., Williford, K.H., Ushikubo, T., Sugitani, K., Mimura, K., Spicuzza, M.J., and Valley, J.W. (2013) Texture-specific isotopic compositions in $3.4 \mathrm{Gyr}$ old organic matter support selective preservation in cell-like structures. Geochim Cosmochim Acta 112:66-86.

Oehler, D.Z., Robert, F., Walter, M.R., Sugitani, K., Allwood, A., Meibom, A., Mostefaoui, S., Selo, M., Thomen, A., and Gibson, E.K. (2009) NanoSIMS: insights to biogenicity and syngeneity of Archaean carbonaceous structures. Precambrian Res 173:70-78.

Oehler, D.Z., Robert, F., Walter, M.R., Sugitani, K., Meibom, A., Mostefaoui, S., and Gibson, E.K. (2010) Diversity in the Archean biosphere: new insights from NanoSIMS. Astrobiology 10:413-424.

Picard, A., Kappler, A., Schmid, G., Quaroni, L., and Obst, M. (2015) Experimental diagenesis of organo-mineral structures formed by microaerophilic $\mathrm{Fe}(\mathrm{II})$-oxidizing bacteria. Nat Commun 6, doi:10.1038/ncomms7277.

Rainey, D.K. and Jones, B. (2010) Preferential soft-tissue preservation in the Hot Creek carbonate spring deposit, British Columbia, Canada. Sediment Geol 227:20-36.

Schopf, J.M. (1975) Modes of fossil preservation. Rev Palaeobot Palynol 20:27-53.

Schopf, J.W. (1993) Microfossils of the early Archean apex chert-new evidence of the antiquity of life. Science 260: 640-646.

Sugitani, K., Grey, K., Allwood, A., Nagaoka, T., Mimura, K., Minami, M., Marshall, C.P., Van Kranendonk, M.J., and Walter, M.R. (2007) Diverse microstructures from Archaean chert from the Mount Goldsworthy-Mount Grant area, Pilbara Craton, Western Australia: microfossils, dubiofossils, or pseudofossils? Precambrian Res 158:228-262. 
Sugitani, K., Grey, K., Nagaoka, T., and Mimura, K. (2009) Three-dimensional morphological and textural complexity of Archean putative microfossils from the Northeastern Pilbara Craton: indications of biogenicity of large $(>15 \mu \mathrm{m})$ spheroidal and spindle-like structures. Astrobiology 9:603-615.

Sugitani, K., Lepot, K., Nagaoka, T., Mimura, K., Van Kranendonk, M., Oehler, D.Z., and Walter, M.R. (2010) Biogenicity of morphologically diverse carbonaceous microstructures from the $c a$. 3400 Ma Strelley Pool Formation, in the Pilbara Craton, Western Australia. Astrobiology 10:899-920.

Sugitani, K., Mimura, K., Lepot, K., Takeuchi, M., Ito, S., and Javaux, E.J. (2015) Early evolution of large microorganisms with cytological complexity revealed by microanalyses of 3.4 Ga organic-walled microfossils. Geobiology 13:507-521.

Thomen, A., Robert, F., and Remusat, L. (2014) Determination of the nitrogen abundance in organic materials by NanoSIMS quantitative imaging. J Anal At Spectrom 29:512-519.

Walsh, M.M. (1992) Microfossils and possible microfossils from the early Archean Onverwacht Group, Barberton mountain land, South Africa. Precambrian Res 54:271-293.

Watanabe, K., Naraoka, H., Wronkiewicz, D.J., Condie, K.C., and Ohmoto, H. (1997) Carbon, nitrogen, and sulfur geochemistry of Archean and Proterozoic shales from the Kaapvaal Craton, South Africa. Geochim Cosmochim Acta 61:3441-3459.
Address correspondence to: Frédéric Delarue

IMPMC Sorbonne Universités-MNHN

UPMC Univ Paris 06

UMR CNRS 7590

IRD UMR 206

61 rue Buffon

F-75005 Paris

France

E-mail: fdelarue@mnhn.fr

Submitted 10 May 2016

Accepted 14 April 2017

\begin{tabular}{|c|}
\multicolumn{1}{c|}{ Abbreviations Used } \\
MNHN $=$ National Museum of Natural History \\
NanoSIMS $=\begin{array}{l}\text { nanoscale secondary ion mass spectrometry } \\
\text { nanoscale secondary ion mass } \\
\text { spectrometer }\end{array}$ \\
ROIs $=$ regions of interest \\
SEM $=$ scanning electron microscopy \\
TLM $=$ transmission light microscopy
\end{tabular}

